\title{
Effect of the boron content on the amorphisation process and magnetic properties of the mechanically alloyed $\mathrm{Fe}_{92-\mathrm{x}} \mathrm{Nb}_{8} \mathrm{~B}_{\mathrm{x}}$ powders
}

\author{
T. Chabi ${ }^{1}$, N. Bensebaa ${ }^{1}$, S. Alleg ${ }^{1, *}$, S. Azzaza ${ }^{1}$, J.J. Suñol ${ }^{2}$, E.K. Hlil ${ }^{3}$ \\ ${ }^{1}$ Laboratoire de magnétisme et Spectroscopie des Solides (LM2S), Département de Physique, \\ Université Badji Mokhtar Annaba, BP 12, 23000 Annaba, Algeria. \\ ${ }^{2}$ Dept. De Fisica, Universitat de Girona, Campus Montilivi, 17071 Girona, Spain. \\ ${ }^{3}$ Institut NEEL, CNRS, Université Grenoble Alpes, 25 Rue des Martyrs BP 166 \\ 38042 Grenoble cedex 9, France. \\ * Corresponding author e-mail address: safia.alleg@univ-annaba.dz \\ Tel/fax: +213774312482
}

\begin{abstract}
:
The effect of the B content on the microstructural, structural and magnetic properties of partially amorphous $\mathrm{Fe}_{92-\mathrm{x}} \mathrm{Nb}_{8} \mathrm{~B}_{\mathrm{x}}(\mathrm{x}=5,10,15$ and 20) alloys have been investigated by means of scanning electron microscopy, X-ray diffraction, BS1 and BS2 magnetometers. The XRD results reveal the formation of a nanocomposite structure where nanocrystalline bcc $\alpha$ $\mathrm{Fe}$ and $\mathrm{Fe}_{2} \mathrm{~B}$ phases are embedded into an amorphous matrix. The FeB boride is observed for higher boron contents ( $\mathrm{x}=15$ and 20) and the crystallite sizes are in the range of 7-24 nm. As the $\mathrm{B}$ content increases, the amorphous relative proportion and coercivity increase, whereas the saturation magnetization decreases. An important magnetic hardening occurs by lowering the temperature from 400 to $5 \mathrm{~K}$ for $\mathrm{x}=20 \% \mathrm{~B}$. The variation of the Curie temperature can be attributed to the heterogeneity of the amorphous matrix.
\end{abstract}

Keywords: Nanocrystalline materials; Mechanical alloying; Fe-Nb-B alloys; X-ray diffraction; Magnetic properties. 


\section{Introduction}

Mechanical alloying (MA) or high energy ball milling (HEBM) is one of the various techniques used to synthesize nanocrystalline (NC) materials. It is a powder metallurgy method where the starting elemental or prealloyed powders are subjected to a high-speed deformation mechanism $\left(10^{3}\right.$ to $\left.10^{-3} \mathrm{~s}^{-1}\right)$ by heavy plastic deformation, fracture, cold welding, rewelding and agglomeration. The final product is achieved by controlling several parameters which are related to each other such as the ball mill type, milling time, milling temperature, ball to-powder weight ratio (BPR), rotation speed, process control agent, grinding media (balls, material, volume of the vial...), and milling atmosphere. HEBM has proved its suitability and availability as one of the powerful and simple techniques for producing amorphous alloys, nanostructured materials, solid solutions and intermetallics [1-10].

The FeMB alloys ( $\mathrm{M}=\mathrm{Zr}$, Hf, $\mathrm{Nb}$ ) or Nanoperm, which contain around $80 \%$ of iron, $7 \%$ of transition metals $(\mathrm{Zr}, \mathrm{Hf}, \mathrm{Nb}$ ) and $13 \%$ of boron, are structurally and magnetically biphasic since they are composed of hard ferromagnetic nanograins dispersed homogeneously into a soft ferromagnetic amorphous matrix [11]. These materials are very interesting due to their soft magnetic properties such as effective permeability and saturation magnetic flux density [12-15]. Consequently, they can be used in many industrial applications such as telecommunications, power electronics, micro-devices, generators and sensors. The augmentation of both $\mathrm{B}$ and $\mathrm{Nb}$ percentages in the Fe-based amorphous alloys play a main role in the thermal stability [10]. The outcome is that the nanocrystallization takes place in the form of pure iron crystals which favor a high saturation induction (1.5-1.7 T) and a Curie temperature, Tc, close to $769^{\circ} \mathrm{C}$. Furthermore, Nanoperm alloys lose their magnetization with the formation of borides [16]. Among the nanoperm, the ternary Fe-Nb-B system has attracted much attention owing to its useful properties [17-19], and has been prepared in ribbons form by melt spinning [20] and planar flow casting [21], bulk form by arc melting [15] and powder form by MA [18]. Depending on the B content, it has been reported that the end product consists, generally, of a mixture of bcc $\alpha$-Fe, borides and amorphous phases [22]. In the ball milled $\mathrm{Fe}_{94-x} \mathrm{Nb}_{6} \mathrm{~B}_{x}(x=9,14,20)$ alloys, it has been found that the Fe lattice parameter increases with increasing $\mathrm{B}$ content while the crystallite size decreases [23] and the boron atoms segregate at the grain boundaries [7]. The $\mathrm{Fe}_{65+\mathrm{x}} \mathrm{Nb}_{10} \mathrm{~B}_{25-\mathrm{x}}(\mathrm{x}=0,5,10)$ metallic glasses prepared by arc melting exhibit soft magnetic properties in the glassy state and their nanocrystallization leads to the enhancement of the coercivity [24]. A mixture of $\alpha-\mathrm{Fe}, \mathrm{Nb}(\mathrm{B})$ 
and highly disordered $\mathrm{Fe}(\mathrm{Nb}, \mathrm{B})$ solid solution has been obtained in the mechanically alloyed $\mathrm{Fe}_{62} \mathrm{Nb}_{8} \mathrm{~B}_{30}$ powders for $25 \mathrm{~h}$, while the paramagnetic amorphous structure is achieved on further milling time [18]. It is obvious that the preparation conditions influence the end product and the properties of the mechanically alloyed powders. Consequently, the aim of the present work is to study the effect of boron content on the amorphisation process, structural, microstructural, morphological and magnetic properties of the ball milled $\mathrm{Fe}_{92-\mathrm{x}} \mathrm{Nb}_{8} \mathrm{~B}_{\mathrm{x}}(\mathrm{x}=5$, 10, 15 and 20) powders. An accurate quantitative phase analysis (QPA) was used to determine the amorphous phase relative proportion by using the MAUD program [25].

\section{Experimental details}

$\mathrm{Fe}_{92-\mathrm{x}} \mathrm{Nb}_{8} \mathrm{~B}_{\mathrm{x}}(\mathrm{x}=5,10,15$ and 20) powder mixtures were mechanically alloyed for $50 \mathrm{~h}$ from pure elemental powders of $\mathrm{Fe}(6-8 \mu \mathrm{m}, 99.7 \%), \mathrm{Nb}(74 \mu \mathrm{m}, 99.85 \%)$ and amorphous $\mathrm{B}$ (>99\%). The milling process was performed in a planetary ball mill Retsch PM400 under an argon atmosphere using hardened steel vials and balls. The ball-to-powder weight ratio was about 7:1 and the rotation speed was $700 \mathrm{rpm}$. In order to avoid the excessive increase of the temperature inside the vials, the milling process was interrupted each $1 / 2 \mathrm{~h}$ for $1 / 4 \mathrm{~h}$. Morphological changes of the powder particles were followed by scanning electron microscopy (SEM) in DSM960A Zeiss apparatus equipped with energy dispersive X-ray spectroscopy (EDX). The structural evolution was investigated by X-ray diffraction (XRD) by means of PANanalytical Empyrean diffractometer in a $(\theta-\theta)$ Bragg Brentano geometry with Co-K $\alpha$ radiation $\left(\lambda_{\mathrm{Co}}=1.78901 \AA\right.$ ). Phase identification, lattice parameters (a, c), average crystallite size, $\langle\mathrm{L}\rangle$, root-mean square (r.m.s) strains, $\left\langle\sigma^{2}\right\rangle^{1 / 2}$, phases relative proportion, atomic positions, etc. were obtained from the refinement of the XRD patterns by the MAUD program which is based on the Rietveld method [26] combined with Fourier analysis which is well adapted for disordered alloys. The saturation magnetization, coercivity, saturation to remanence ratio and Curie temperatures were determined by measuring $M(H)$ hysteresis loops and $M(T)$ curves using the BS1 and BS2 extraction-type magnetometers developed at Néel Institute for high and low temperatures, respectively.

\section{Results and discussion}

\subsection{Morphological evolution}


The powder particles are subjected to flatting, fracturing, cold welding and rewelding

during the milling process. Consequently, the formed fresh surfaces show a high activity which results in strong bonding between the hard phases and the metallic matrix. Figure 1 displays the morphological changes of the ball milled $\mathrm{Fe}_{92-\mathrm{x}} \mathrm{Nb}_{8} \mathrm{~B}_{\mathrm{x}}(\mathrm{x}=5,10,15$ and 20) powders for $50 \mathrm{~h}$. One observes that the powder morphologies are different from each other. The ductile particles are flattened by the compressive forces due to the collision of the balls inside the vials, while the brittle particles (boron) are fractured and welded. Hence, the microforging process causes a change in the shape of the individual particles. The existence of bigger and small particles results from the competition between fracturing and cold welding. For $20 \% \mathrm{~B}$, the important microstructural refinement can be related to the domination of the fracturing process since the boron element is hard and brittle. The EDX analysis shows that each particle contains the initial $\mathrm{Fe}, \mathrm{Nb}$ and $\mathrm{B}$ elements (Table 1). The elemental composition fluctuation might be due to the heterogeneity of the powder particles.

\subsection{Phase formation}

Figure 2 illustrates the evolution of the XRD patterns of the $\mathrm{Fe}_{92-\mathrm{x}} \mathrm{Nb}_{8} \mathrm{~B}_{\mathrm{x}}$ alloys as a function of $\mathrm{B}$ content. The widening of the diffraction peaks and the reduction of their intensities are related to the decrease of the crystallite size and the increase of the internal level strains. In addition to the broad amorphous halo (located at about $2 \theta=529$ ), sharp diffraction peaks linked to $\mathrm{NC} \alpha-\mathrm{Fe}$ and $\mathrm{Fe}_{2} \mathrm{~B}$ phases are observed. For $15 \% \mathrm{~B}$ and $20 \% \mathrm{~B}$ samples, one notes also the appearance of new diffraction peaks related to the formation of the FeB boride. Accordingly, the Rietveld refinements of the XRD patterns were performed by introducing either three or four phases among the following structures: bcc $\alpha$-Fe (space group $\mathrm{Im} 3 \mathrm{~m}$, lattice parameter $\mathrm{a}_{0}=0.2866 \mathrm{~nm}$ ), tetragonal $\mathrm{Fe}_{2} \mathrm{~B}$ boride (space group $14 / \mathrm{mcm}$, lattice parameters $\mathrm{a}_{0}=0.511 \mathrm{~nm}$ and $\mathrm{c}_{0}=0.4249 \mathrm{~nm}$ ), orthorhombic $\mathrm{FeB}$ (space group Pbnm:cab, lattice parameters $\mathrm{a}_{0}=0.4053 \mathrm{~nm}, \mathrm{~b}_{0}=0.5495 \mathrm{~nm}$ and $\mathrm{c}_{0}=0.2946 \mathrm{~nm}$ ) and amorphous phase (Fig. 3). This later was quantified according to Le Bail model [25] by keeping $\langle\mathrm{L}\rangle=10 \mathrm{~nm}$ and $\left\langle\sigma^{2}\right\rangle^{1 / 2}=0.001$, while the lattice parameter is refined. The obtained results are summarized in Table 2.

The presence of the metalloid $\mathrm{B}$ in the $\mathrm{Fe}-\mathrm{Nb}-\mathrm{B}$ alloys obstructs coarsening of the bcc grains, enhances the glass forming ability (GFA), provides good magnetic properties and gives a better thermal stability of the residual amorphous phase [27]. Moreover, the formation of the amorphous phase in the mechanically alloyed Fe-Nb-B system can be related to the 
important amount of structural defects and impurity atoms in the interstitial sites which distorted locally the crystal lattice. Consequently, the interdiffusion between the elemental powders is accelerated and the free energy of the crystalline phases is enlarged compared to the free energy of the amorphous ones leading to an atomic disorder and facilitating the amorphisation process. Furthermore, the packed local structure is favored by the segregation of boron inclusions at the grain boundaries, the stronger attractive interaction between $\mathrm{Fe}$ and $\mathrm{B}$ atoms as well as the presence of three elements ( $\mathrm{Fe}, \mathrm{Nb}$ and $\mathrm{B}$ ) with significant difference in atomic size ratios $\left(\mathrm{r}_{\mathrm{Nb}}=0.198 \mathrm{~nm}>r_{\mathrm{Fe}}=0.124 \mathrm{~nm}>r_{\mathrm{B}}=0.087 \mathrm{~nm}\right)$. When the local atomic strains generated by size differences between $\mathrm{B}, \mathrm{Nb}$ and $\mathrm{Fe}$ attain a critical level, the local atomic coordination number changes and the topological instability of the crystalline lattice leads to the formation of the amorphous phase. This later occurs at the $\mathrm{Fe} / \mathrm{B}, \mathrm{Fe} / \mathrm{Nb}$ and $\mathrm{Nb} / \mathrm{B}$ interfaces and the mixing of the elemental powders at the atomic level is favored by the high negative heats of mixing which are of about $-26 \mathrm{~kJ} / \mathrm{mol},-16 \mathrm{~kJ} / \mathrm{mol}$ and $-54 \mathrm{~kJ} / \mathrm{mol}$ for $\mathrm{Fe}$ $\mathrm{B}, \mathrm{Nb}-\mathrm{Fe}$ and $\mathrm{Nb}-\mathrm{B}$ [28], respectively. Furthermore, the formation of the amorphous phase can be accelerated by the increase of the boron content. Indeed, in the Fe-based alloys with less than 12 at.\% B a metastable bcc $\mathrm{Fe}(\mathrm{B})$ supersaturated solid solution was obtained instead of an amorphous phase [18, 29].

The formation of $\mathrm{Fe}_{2} \mathrm{~B}$ and $\mathrm{FeB}$ iron borides can be attributed to the reaction between Fe and B with similar diffusion coefficients [30] as well as the excess of boron content which is introduced into the Fe matrix during the milling process, although its solubility is less than 0.02 wt.\% at room temperature [31]. Besides, the diffusivity of solute elements into the iron matrix might be enhanced by the presence of a variety of crystal defects (dislocations, vacancies, stacking faults and grain boundaries) that are introduced by the heavy plastic deformation into the powder particles. Consequently, the refined microstructural features decrease the diffusion distances and the slight increase in temperature during the milling process helps the diffusion process leading to the formation of intermetallic compounds. According to the binary $\mathrm{Fe}-\mathrm{B}$ phase diagram [31], $\mathrm{Fe}_{2} \mathrm{~B}$ and $\mathrm{FeB}$ boride phases can be formed at the thermodynamic equilibrium with a B content of about $8.8 \mathrm{wt} \%$ and $16 \mathrm{wt} \%$, respectively.

The crystallite size of the obtained phases varies between 7 and $24.3 \mathrm{~nm}$. One notes that the $\alpha-F e$ crystallite size increases as a function of B content (Table 2), while that of the $\mathrm{Fe}_{2} \mathrm{~B}$ phase remains constant (Fig.4). The relative proportion of $\mathrm{Fe}_{2} \mathrm{~B}$ phase (Fig. 5) incresases to $38.9 \%$ for $10 \% \mathrm{~B}$, decreases for $15 \% \mathrm{~B}$ and levels off. This decrease might be correlated to 
the segregation of $\mathrm{B}$ atoms in the grain boundaries. Such particular behavior might be ascribed to the instability of the segregation process and its effect can be inhibited beyond this critical concentration. Similar comportment was observed in the $\mathrm{Fe}_{60} \mathrm{Al}_{40-x} \mathrm{~B}_{x}$ alloys [32].

The lattice parameter of $\alpha$-Fe is B content independent (Fig. 6) while that of the highly disordered amorphous type structure increases relatively. Such an increase might be due to its enrichment by the $\mathrm{Nb}$ atoms. For the $\mathrm{Fe}_{2} \mathrm{~B}$ boride phase, the lattice parameters $a$ and $c$ exhibit an antagonist behavior as a function of B content (Fig. 7). Indeed, the lattice parameter $a$ decreases linearly whereas $c$ increases slightly up to $15 \% \mathrm{~B}$ and then rapidly for $20 \% \mathrm{~B}$. The relative deviations of the lattice parameters $a$ and $c$ are of about $\Delta a=-1 \%$ and $\Delta \mathrm{c}=1.82 \%$. The lattice distortion which is characterized by lattice expansion and/or contraction can be attributed to the presence of a great quantity of point defects or vacancies inside the nanometer crystallites due to their higher energetic solution.

\subsection{Magnetic properties}

The hysteresis loops of the mechanically alloyed $\mathrm{Fe}_{92-\mathrm{x}} \mathrm{Nb}_{8} \mathrm{~B}_{\mathrm{x}}$ powders, $\mathrm{M}(\mathrm{H})$, taken at different temperatures, are displayed in Figure 8 as a function of boron content. The insets show the enlargement of the low-field portion of the hysteresis loops as well as the first magnetization curves. The magnetic properties are dependent on the sample microstructure such as crystallite size, particle morphology, structural defects, etc. The hysteresis curves display typical soft magnetic characteristics and the steep augmentation in $M(H)$ near $\mu_{0} H_{a}=0$ can be due to domain-wall movement. Figure 9 reveals that the variation of coercivity $H c$ as a function of $\mathrm{B}$ content exhibits the same trend as that of the amorphous phase proportion. Indeed, $H_{c}$ increases with the augmentation of B content. Furthermore, the magnetic hardening at low temperatures is evidenced by the important increase of coercive field for $20 \% \mathrm{~B}$ sample from 0.014 to $0.0595 \mathrm{~T}$ by lowering the temperature from 400 to $5 \mathrm{~K}$, respectively. The augmentation of $H_{c}$ might be linked to the presence of small precipitates within the hard magnetic phase. For example, boron is a brittle and hard material and consequently, boron inclusions remain without mixing in the matrix even after mechanical amorphization of the material. Also, the very small miscibility of $\mathrm{Fe}, \mathrm{Nb}$ and $\mathrm{B}$ leads to the presence of unmixed inclusions within the amorphous phase which impede the domain wall movement leading to the increase of coercivity. Such an assumption can be confirmed by the increase of the amorphous phase relative proportion as a function of $\mathrm{B}$ content. Simultaniously, the saturation magnetization $M s$ decreases with increasing B content as 
shown in Figure 10. The drop of $M s$ might be due to the formation of the hard magnetic phase $\mathrm{Fe}_{2} \mathrm{~B}$ as well as to the structural disorder which is introduced during the milling process. Consequently, the magnetic moment decreases through the change in the configuration of the nearest neighbors of magnetic $\mathrm{Fe}$ atoms via the substitution of $\mathrm{Fe}$ atoms by $\mathrm{Nb}$ and/or $\mathrm{B}$ ones. In fact, the magnetic atomic moment is assumed to depend on the number of magnetic and metalloid atoms in the first nearest-neighbor shell. Therefore, the decrease of $M s$ can be correlated to the decrease of the coordination of nearest-neighbor magnetic atoms due to the high metalloid content at.\% $(\mathrm{Nb}+\mathrm{B})$. Comparable results have been reported on the decrease of $M s$ as the formation of the amorphous phase is accelerated [6]. The remanence to saturation ratio, $M r / M s$, is plotted against B content for different temperatures in Figure 11. By comparing the $M r / M s$ values with those of the models based on the displacement of the domain walls [33] and experimental results, 5\%, $10 \% \mathrm{~B}$ and $15 \% \mathrm{~B}$ samples are multidomains $(\mathrm{Mr} / \mathrm{Ms}<0.1)$ for all temperatures. Furthermore, $20 \% \mathrm{~B}$ sample is multidomain for $400 \mathrm{~K}$ and pseudo-single domains $(0.1<M r / M s<0.5)$ for 5,200 and $300 \mathrm{~K}$.

Figure 12 represents the normalized temperature dependence magnetization $\mathrm{M}-\mathrm{T}$ of the $\mathrm{Fe}_{92-\mathrm{x}} \mathrm{Nb}_{8} \mathrm{~B}_{\mathrm{x}}(\mathrm{x}=5,10,15$ and 20) alloys measured under a magnetic field of $0.05 \mathrm{~T}$ in the temperature range of 200-750 K. For lower and higher boron contents, the magnetization curves exhibit different behavior. In fact, the magnetization shows an increase at about $400 \mathrm{~K}$ and $670 \mathrm{~K}$ for $20 \% \mathrm{~B}$ and $5 \% \mathrm{~B}$, respectively, that can be attributed to the crystallization of the amorphous phase. On further heating of the $5 \% \mathrm{~B}$ sample beyond $740 \mathrm{~K}$, the decrease of the magnetization to zero can be associated with the ferromagnetic-paramagnetic transition of the $\alpha-\mathrm{Fe}(\mathrm{Nb}, \mathrm{B})$ solid solution. The effect of the boron content on the composition of the amorphous phase and therefore, the magnetic transition temperature is evidenced by the thermal derivative of the magnetization with respect to the temperature, dM/dT (Fig. 13). The Curie temperature $(\mathrm{Tc})$ increases with increasing $\mathrm{B}$ content up to $15 \% \mathrm{~B}$ and then decreases for $20 \% \mathrm{~B}$. Tc depends on the exchange interaction between the magnetic moments, which in turn depends on the distance between the magnetic atoms. Consequently, Tc depends on the composition of the amorphous structure. Also, the increase of Tc might come from the penetration of the exchange field caused by the $\mathrm{NC} \alpha-\mathrm{Fe}$ into the residual amorphous matrix [34]. It is well known that $\mathrm{B}$ and $\mathrm{Nb}$ have different effects on $\mathrm{Tc}$, while $\mathrm{B}$ generates strong intergranular magnetic coupling, leading to the increase of $\mathrm{Tc}, \mathrm{Nb}$ reduces the intergranular coupling thereby decreasing Tc. Thus, the increase of Tc might be related to the $\mathrm{B}$ effect while its decrease in the case of $20 \% \mathrm{~B}$ can be due to the presence of $\mathrm{Nb}$ atoms in the vicinity 
of Fe ones. It seems that the overall composition of the residual amorphous phase, rather than the unmixed $\mathrm{Fe}$ content alone, appears to determine $\mathrm{Tc}$ of the milled powders. Also, the broader peaks in $\mathrm{dM} / \mathrm{dT}$ curves point out the existence of an inhomogeneous atomic order which results in spreading of the local Tc. This can be due to the hardness and brittlness of boron on the one hand, and its very low solubility in $\mathrm{Fe}$ on the other hand. The broadening of the magnetic transition can be linked to the multiphase character of the mechanically alloyed FeNbB system, the presence of impurity phases such as remnant inclusions [6], or the existence of a distribution of Tc in amorphous phases.

\section{Conclusions}

$\mathrm{Fe}_{92-\mathrm{x}} \mathrm{Nb}_{8} \mathrm{~B}_{\mathrm{x}}(\mathrm{x}=5,10,15$ and 20) powder mixtures have been prepared by MA. The end product consists of an amorphous structure, $\mathrm{NC} \alpha-\mathrm{Fe}$ and $\mathrm{Fe}_{2} \mathrm{~B}$ phases. $\mathrm{FeB}$ boride is observed for 15 and $20 \% \mathrm{~B}$ samples. The crystallite sizes are in the range of 7-24.3 nm and the volume fraction of the disordered amorphous phase increases with increasing B content, and reaches a maximum value of about $66 \%$ for $20 \% \mathrm{~B}$. As B content increases, $H_{c}$ increases and $M_{s}$ decreases. The magnetic hardening is evidenced by the important augmentation of $H_{c}$ for $20 \% \mathrm{~B}$ sample from 0.014 to $0.0595 \mathrm{~T}$ by lowering the temperature from 400 to $5 \mathrm{~K}$, respectively. Tc of the amorphous phase rises with increasing B content up to $15 \% \mathrm{~B}$ and then decreases.

\section{Acknowledgements}

This work has been supported by the Algerian Ministère de l'Enseignement Supérieur et de la Recherche Scientifique, the PHC-Maghreb 15 MAG07 program and the Spanish MINECO projects MAT2013-47231-C2-2-P and MAT2016-75967-P.

\section{References}

[1] Alleg, S., Ibrir , M., Fenineche, N.E., Azzaza, S., Suñol, J.J., J. Alloys Compds., 494, 109115 (2010).

[2] Bensebaa, N., Loudjani, N., Alleg, S., Dekhil, L., Suñol, J.J., Al Sae, M., Bououdina, M.: J. Magn. Magn. Mater. 349, 51 (2014).

[3] Alleg, S. In: Barker, J.M. (ed.) Powder Engineering, Technology and Applications, pp. 81-124 Nova Science Publishers, Inc. (2011). 
[4] Azzaza, S., Alleg, S., Suñol, J.J.: J. Therm. Analy. Calo. 119, 1037-1046 (2015).

[5] Bensebaa, N., Alleg, S., Grenèche, J. M., J. Alloys Compds 393 194-203 (2005).

[6] Ipus, J.J., Blázquez, J.S., Conde, C.F., Borrego, J.M., Franco, V., Lozano-Pérez, S., Conde, A., Intermetallics 49, 98-105 (2014).

[7] Blázquez J.S., Ipus J.J., Conde C.F., Conde, A., J. Alloys Compds 615, S555-S558 (2014).

[8] Alleg, S., Souilah, S., Younes, A., Bensalem, R., Suñol, J.J., Greneche, J.M.: J. Alloys Compds. 536S, S394-S397 (2012).

[9] Varga, L.K., Bakos, E., Koszó, E.K., Zsoldos, E., Kiss, L.F., J. Magn. Magn. Mater. 133, 280 (1994).

[10] Suñol, J.J., Güella, J.M., Bonastrea, J., Alleg, S., J. Alloys Compds 483, 604-607 (2009).

[11] Ling-fei, C., Ming-pu, W., Dan, X., Ming-xing, G., Zhou, L., Gen-ying, X.: Trans. Non ferrous Met. Soc. China 16, 299-303 (2006).

[12] Ipus, J. J., Blazquez, J.S., Franco, V., Conde, A., Kiss, L. F., Intermetallics 18, 565-568 (2010).

[13] Blázquez J.S., Ipus J.J., Conde C.F., Conde, A.: J. Alloys Compds 615, S555-S558 (2014).

[14] Li, W., Yang, Y. Z., Xu, J., Xie, C. X., J Supercond Nov Magn 30, 1877 (2017).

[15] Stoica, M., Hajlaoui, K., Das, J., Eckert, J., Yavari, A.R., Rev. Adv. Mater. Sci 18, 61-65 (2008).

[16] Varga, L.K., Bakos, E., Koszó, E.K., Zsoldos, E., Kiss, L.F., J. Magn. Magn. Mater. 133, 280 (1994).

[17] Balogh, J., Kemény, T., Vincze, I., Budjosó, L., Tóth, L., Vincze, G., J.,Appl. Phys. 77, (1995) 4997.

[18] Alleg, S., Hamouda, A., Bensalem, R., Suñol, J.J., Grenèche, J.M., Azzaza, S.: Mater. Chem. Phys. 122, 35-40 (2010).

[19] Calca, A., Radlinski, A. P.: Mater. Sci. Eng. 134, 1350-1353 (1991).

[20] Imafuku, M., Sato, S., Koshiba, H., Matsubara, E., Inoue, A., Scripta mater. 44, $2369-$ $2372(2001)$.

[21] Životský, O., Postava, K., Kraus, L., Jirásková, Y., Juraszek, J., Teillet, J., Barčová, K., Švec, P., Janičkovič, D., Pištora, J., J. Magn. Magn. Mater. 320 1535-1540 (2008).

[22] Škorvánek, I., Kováč, J., Marcin, J., Duhaj, P., Gerling, R.: J. Magn. Magn. Mater. 203, 226-228 (1999).

[23] Suñol, J.J., González, A., Saurina, J., Escoda, L., Bruna, P.: Mater. Sci. Engin. A 
375-377, 874-880 (2004).

[24] Torrens-serra, J., Bruna, P., Rodriguez-Viejo, J., Roth, S., and Clavaguera-Mora, M. T., Intermetallics 18, 773-780 (2010).

[25] Lutterotti, L.: MAUD version 2.55, http://maud.radiographema.com/

[26] Rietveld, H.M., J. Appl. Cryst. 2, 65-71 (1969).

[27] Blasquez, J.S., Franco, V., Conde, C.F., Conde, A., Intermetallics 15, 1351-1360 (2007).

[28] Takeuchi, A., Inoue, A., Mater. Trans. 46, 2817-2829 (2005).

[29] Hasegawa, R., Ray, R., J. Appl. Phys. 494174 (1978).

[30] Azzaza, S., PhD Thesis University of Annaba, Algeria (2009).

[31] Massalski, T.B.: Binary alloy phase diagrams, 2nd Edn. ASM International, Materials Park, Ohio (1990)

[32] Rico, M.M., Grenèche, J.M., Alcazar, G.A.P., J. Alloys Compd. 398, 26-32 (2005).

[33] Fallot, M. : Masson et Cie (1935).

[34] Hernando, A., Amils, X., Nogués, J., Suriñach, S., Baró, M.D., Ibarra, M.R.: Phys. Rev. B 58, R11 864 (1998). 


\section{Figure captions}

Figure 1: SEM micrographs of $\mathrm{Fe}_{92-\mathrm{x}} \mathrm{Nb}_{8} \mathrm{~B}_{\mathrm{x}}$ powders. The insets show the EDX analysis.

Figure 2: XRD patterns of $\mathrm{Fe}_{92-\mathrm{x}} \mathrm{Nb}_{8} \mathrm{~B}_{\mathrm{x}}$ powders.

Figure 3: Rietveld refinement of the XRD patterns of $\mathrm{Fe}_{92-\mathrm{x}} \mathrm{Nb}_{8} \mathrm{~B}_{\mathrm{x}}$ powders.

Figure 4: $\mathrm{B}$ content dependence of the crystallite size of $\mathrm{Fe}_{2} \mathrm{~B}$.

Figure 5: Evolution of the phases relative proportions as a function of B content.

Figure 6: Lattice parameters evolution against B content of bcc $\alpha-\mathrm{Fe}$ and amorphous phase.

Figure 7: Lattice parameters evolution of $\mathrm{Fe}_{2} \mathrm{~B}$ boride phase as a function of $\mathrm{B}$ content.

Figure 8: Hysteresis loops of the $\mathrm{Fe}_{92-\mathrm{x}} \mathrm{Nb}_{8} \mathrm{~B}_{\mathrm{x}}(\mathrm{x}=5,10,15$ and 20) powders , taken for different temperatures. The inset shows the enlargement of the central part and the first magnetization curve .

Figure 9: Variation of coercivity, $H c$, and amorphous phase proportion as a function of B content.

Figure 10: Evolution of saturation magnetization, $M s$, and amorphous phase proportion $v s$. B content.

Figure 11: Changes of squarness ratio, $\mathrm{Mr} / \mathrm{Ms}$, against B content.

Figure 12: Temperature dependence magnetization $\mathrm{M}-\mathrm{T}$ of the $\mathrm{Fe}_{92-\mathrm{x}} \mathrm{Nb}_{8} \mathrm{~B}_{\mathrm{x}}$ compounds measured under a magnetic field of $0.05 \mathrm{~T}$.

Figure 13: $\mathrm{dM} / \mathrm{dT}$ variation as a function of temperature. 


\section{Table captions}

Table 1: EDX analysis of the $\mathrm{Fe}_{92-\mathrm{x}} \mathrm{Nb}_{8} \mathrm{~B}_{\mathrm{x}}$ powders.

Table 2: Lattice parameters ( $a, b$ and $c$ ), crystallite size, $\langle\mathrm{L}\rangle$, microstrains, $\left\langle\sigma^{2}\right\rangle^{1 / 2}$ and relative proportions of the ball milled $\mathrm{Fe}_{92-\mathrm{x}} \mathrm{Nb}_{8} \mathrm{~B}_{\mathrm{x}}(\mathrm{x}=5,10,15$ and 20) powders for $50 \mathrm{~h}$. 
Table 1

\begin{tabular}{|c|c|c|c|}
\hline \multirow{2}{*}{ Sample } & \multicolumn{3}{|c|}{ Element } \\
\cline { 2 - 4 } & Fe (wt.\%) & Nb (wt. \%) & B (wt. \%) \\
\hline 5\% B & 76.27 & 1.71 & 22.92 \\
\hline $\mathbf{1 0 \%}$ B & 62.93 & 2.46 & 34.61 \\
\hline $\mathbf{1 5 \%}$ B & 94.13 & 4.38 & 1.49 \\
\hline 20\% B & 72.7 & 2.64 & 24.66 \\
\hline
\end{tabular}

Table 2

\begin{tabular}{|c|c|c|c|c|c|c|c|c|c|c|}
\hline Sample & Phase & $\begin{array}{l}\text { a (nm) } \\
\pm 10^{-4} \\
\end{array}$ & $\Delta \mathbf{a}(\%)$ & $\begin{array}{l}\text { b (nm) } \\
\pm 10^{-4}\end{array}$ & $\Delta \mathrm{b}(\%)$ & $\begin{array}{l}\mathrm{c}(\mathrm{nm}) \\
\pm 10^{-4} \\
\end{array}$ & $\Delta \mathrm{c}(\%)$ & $\begin{array}{c}L L(\mathrm{~nm}) \\
\pm 2\end{array}$ & $\begin{array}{l}\left\langle\sigma^{2}\right\rangle^{1 / 2} \\
\pm 10^{-3} \\
\end{array}$ & Proportions (\%) \\
\hline \multirow[t]{4}{*}{$5 \% \mathrm{~B}$} & $\alpha-\mathrm{Fe}$ & 0.2867 & 0.04 & ---- & ---- & ---- & ---- & 07.45 & 0.62 & 16.0 \\
\hline & $\mathrm{Fe}(\mathrm{B})$ & 0.2899 & 1.15 & ---- & ---- & ---- & ---- & 12.35 & 1.32 & 24.0 \\
\hline & $\mathrm{Fe}_{2} \mathrm{~B}$ & 0.5162 & 1.02 & ---- & ---- & 0.4205 & -1.03 & 08.32 & 0.39 & 12.4 \\
\hline & Amorphous & 0.2897 & ---- & ---- & ---- & ---- & ---- & 10 & 0.001 & 47.6 \\
\hline \multirow[t]{3}{*}{$10 \% \mathrm{~B}$} & $\alpha-\mathrm{Fe}$ & 0.2867 & 0.04 & ---- & ---- & ---- & ---- & 19.60 & 0.39 & 06.4 \\
\hline & $\mathrm{Fe}_{2} \mathrm{~B}$ & 0.5169 & 1.15 & ---- & ---- & 0.4198 & -1.20 & 08.24 & 0.26 & 38.9 \\
\hline & Amorphous & 0.2914 & ---- & ---- & ---- & ---- & ---- & 10 & 0.001 & 54.7 \\
\hline \multirow[t]{4}{*}{$15 \% \mathrm{~B}$} & $\alpha-\mathrm{Fe}$ & 0.2868 & 0.07 & ---- & ---- & ---- & ---- & 23.11 & 0.28 & 29.3 \\
\hline & $\mathrm{Fe}_{2} \mathrm{~B}$ & 0.5173 & 1.23 & ---- & ---- & 0.4194 & -1.29 & 08.10 & 0.98 & 09.6 \\
\hline & $\mathrm{FeB}$ & 0.4080 & 0.66 & 0.5709 & 3.89 & 0.3040 & 3.19 & 10.11 & 0.24 & 04.9 \\
\hline & Amorphous & 0.2927 & ---- & ---- & ---- & ---- & ---- & 10 & 0.001 & 56.2 \\
\hline \multirow[t]{4}{*}{$20 \% \mathrm{~B}$} & $\alpha-\mathrm{Fe}$ & 0.2867 & 0.04 & ---- & ---- & ---- & ---- & 24.28 & 0.32 & 06.9 \\
\hline & $\mathrm{Fe}_{2} \mathrm{~B}$ & 0.5208 & 1.20 & ---- & ---- & 0.4175 & -1.74 & 08.84 & 0.17 & 09.7 \\
\hline & $\mathrm{FeB}$ & 0.4137 & 2.07 & 0.5577 & 1.49 & 0.2972 & 0.88 & 10.69 & 0.43 & 17.4 \\
\hline & Amorphous & 0.2963 & ---- & - - - & - - - & - - - & - - - - & 10 & 0.001 & 66 \\
\hline
\end{tabular}



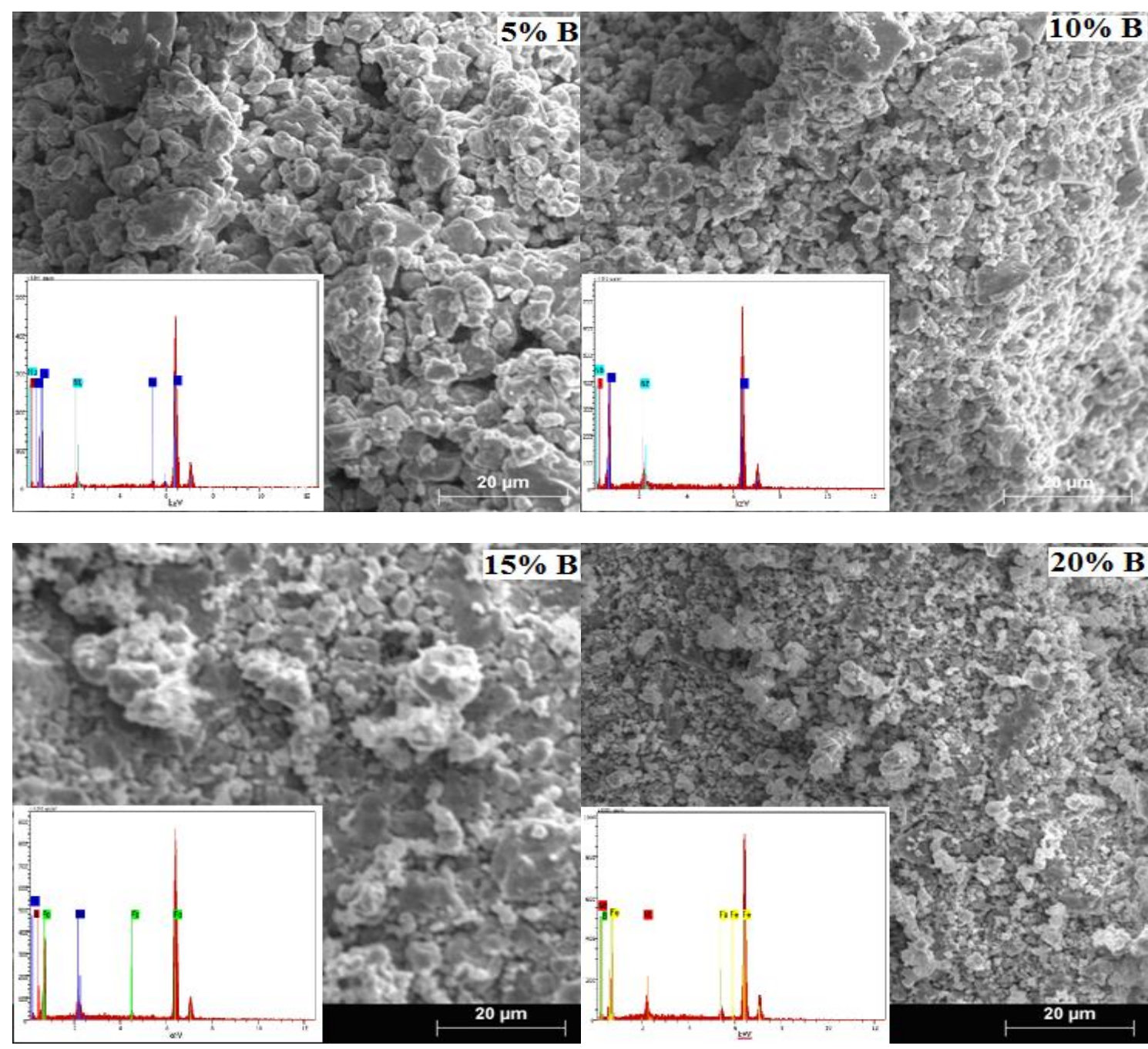

Figure 1

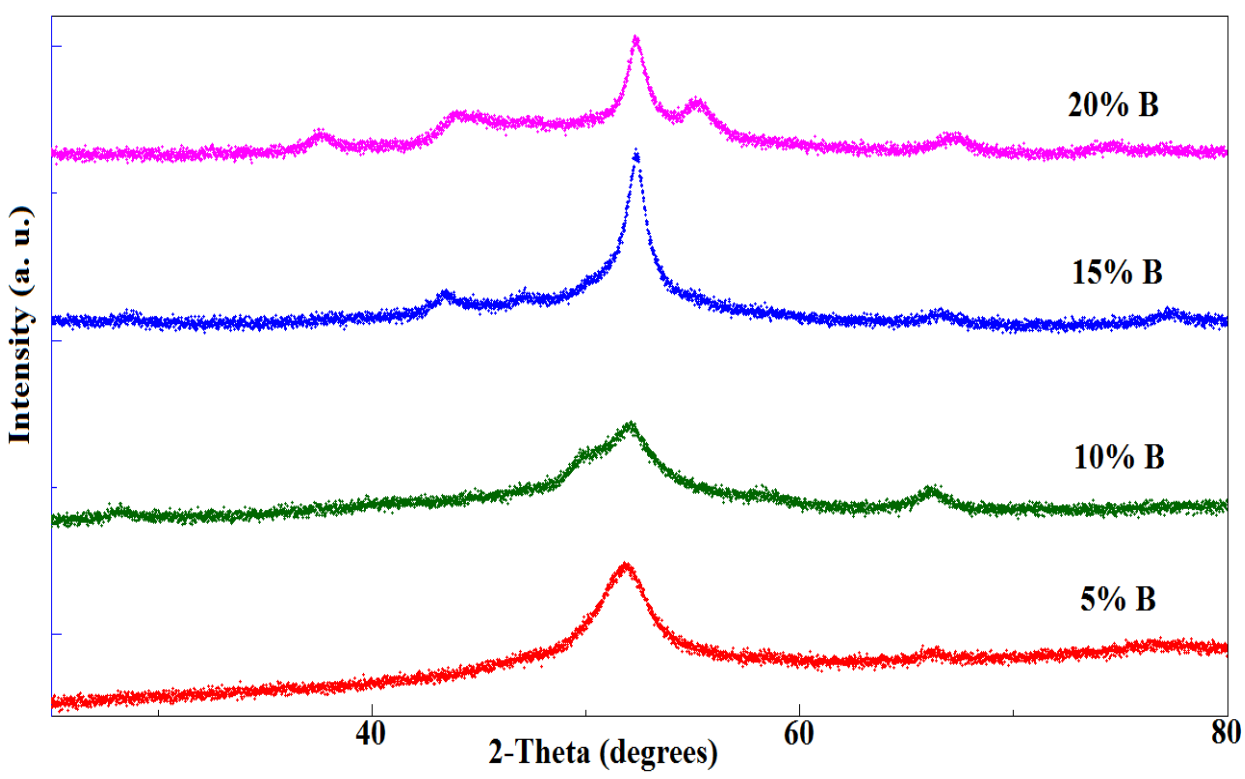

Figure 2 

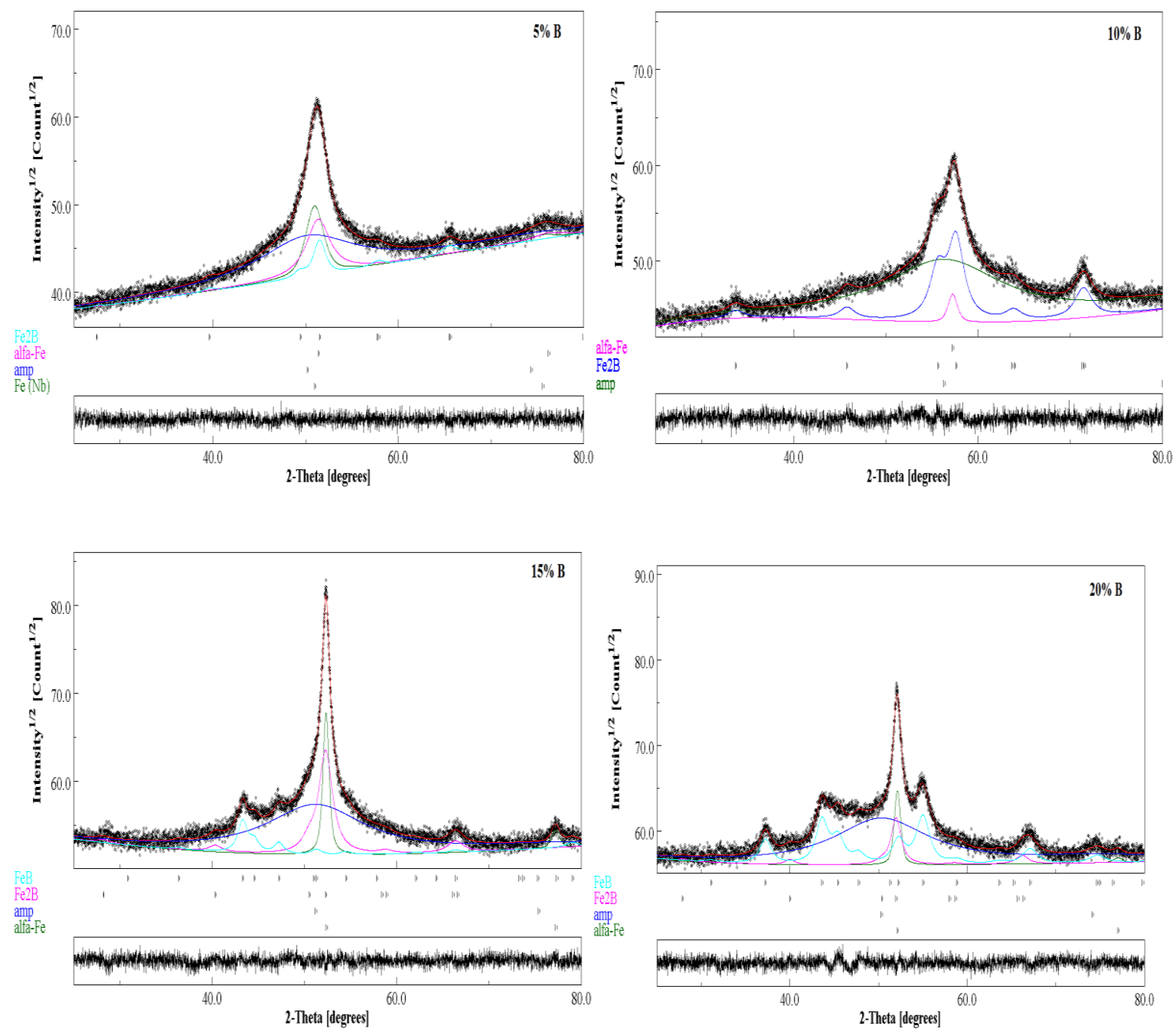

Figure 3 


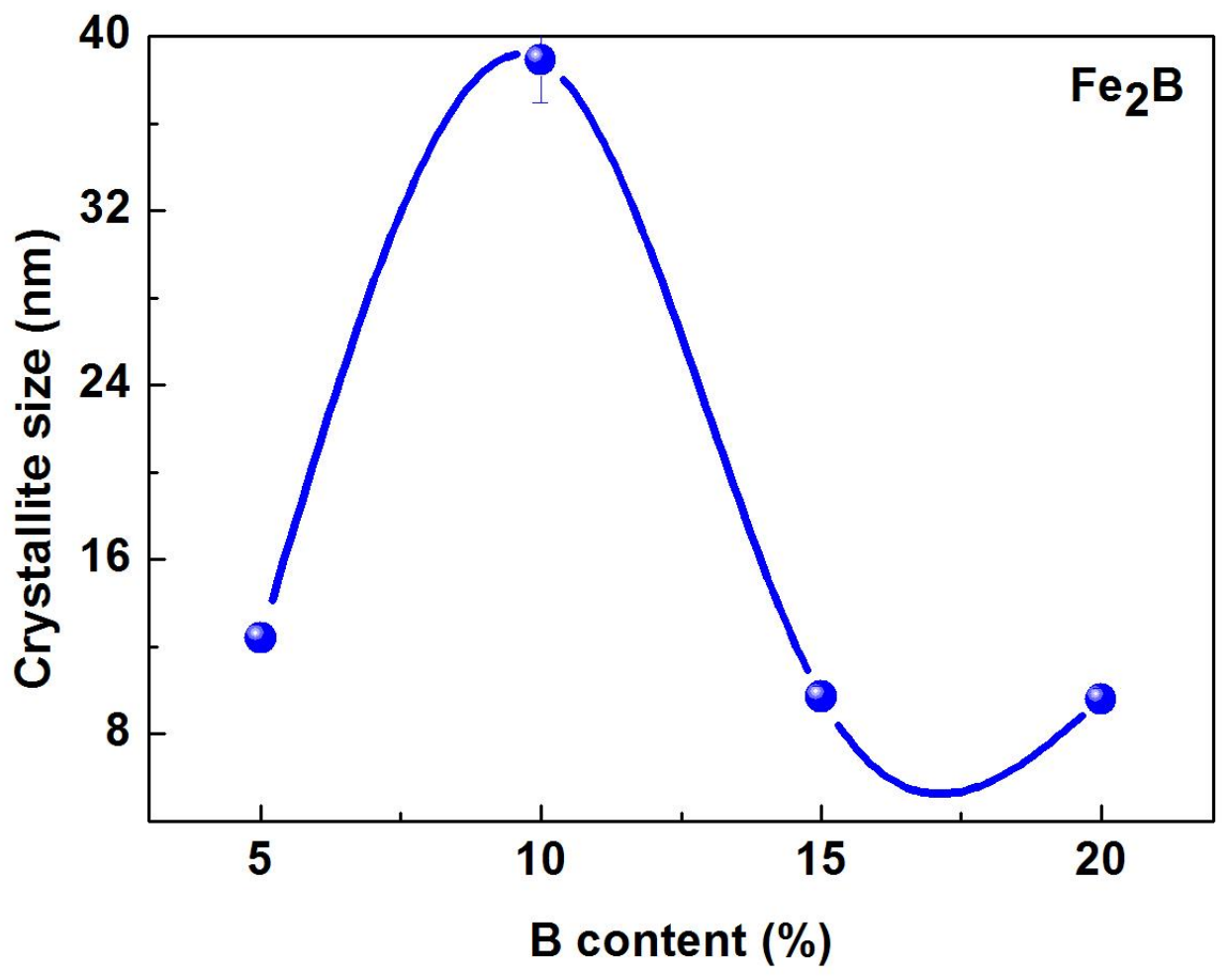

Figure 4

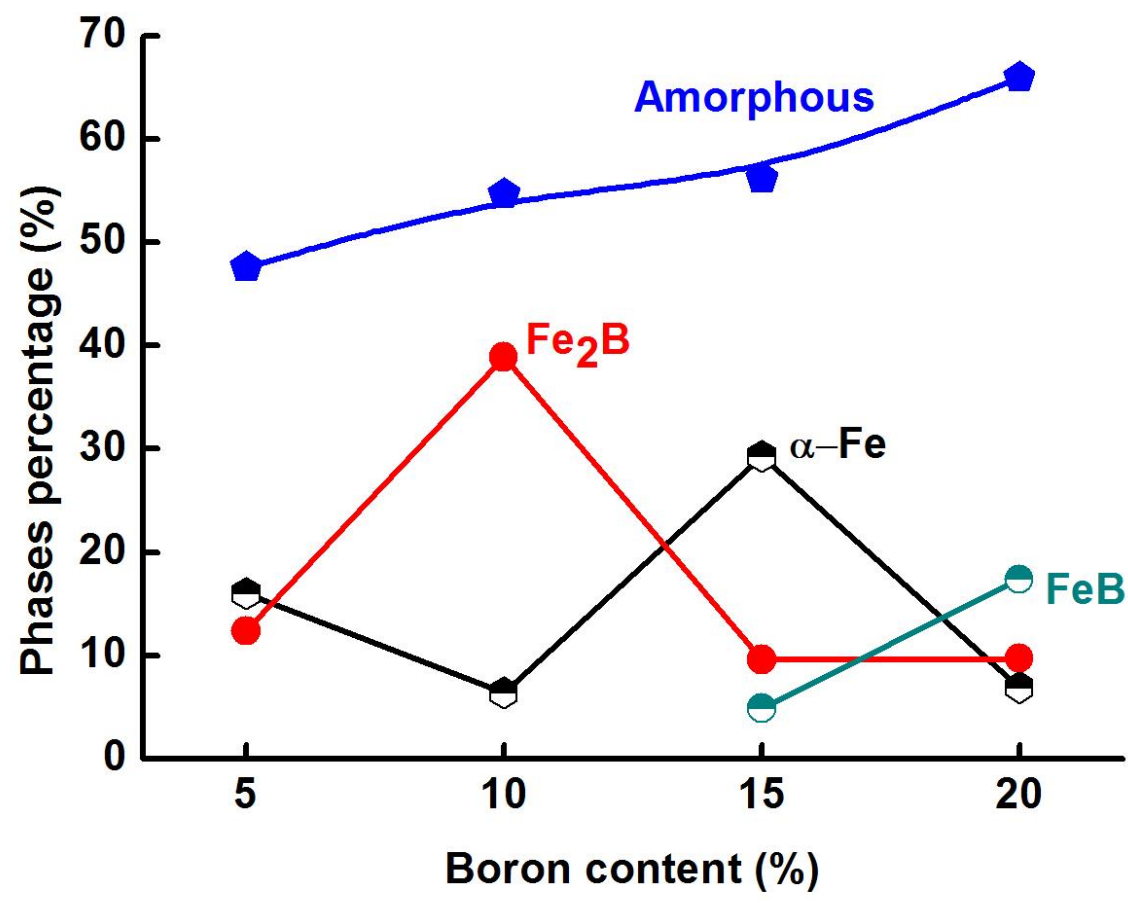

Figure 5 


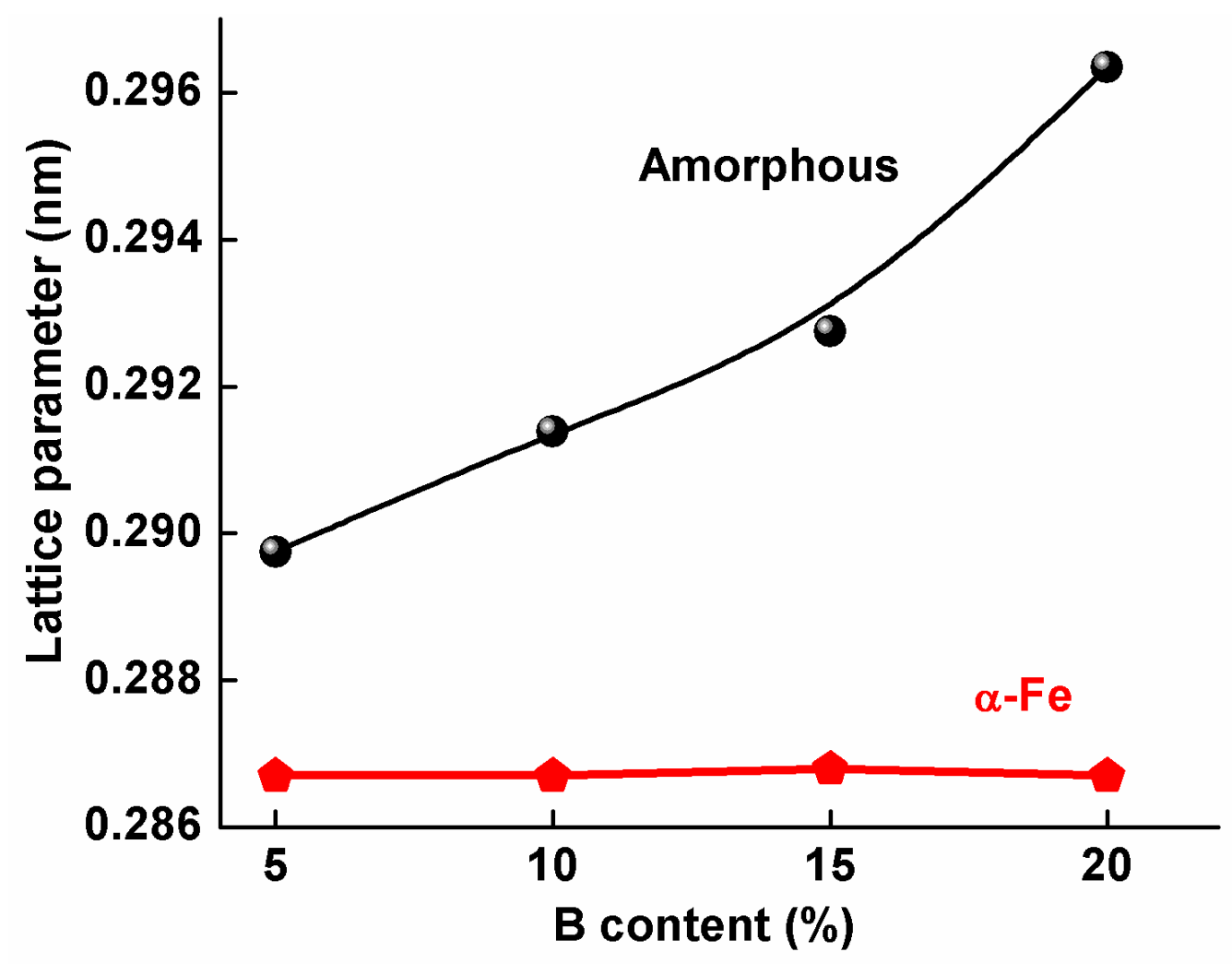

Figure 6

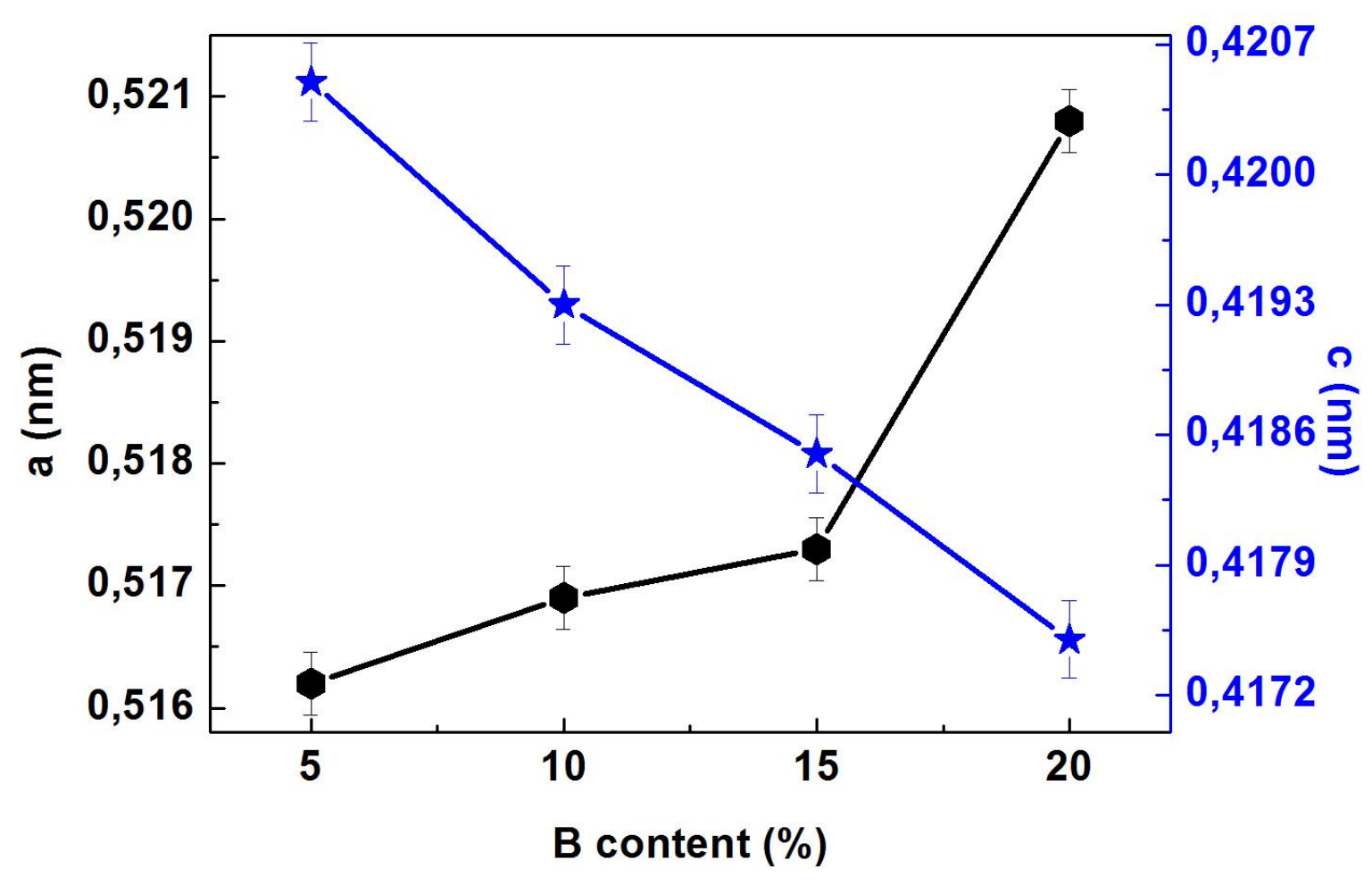

Figure 7 

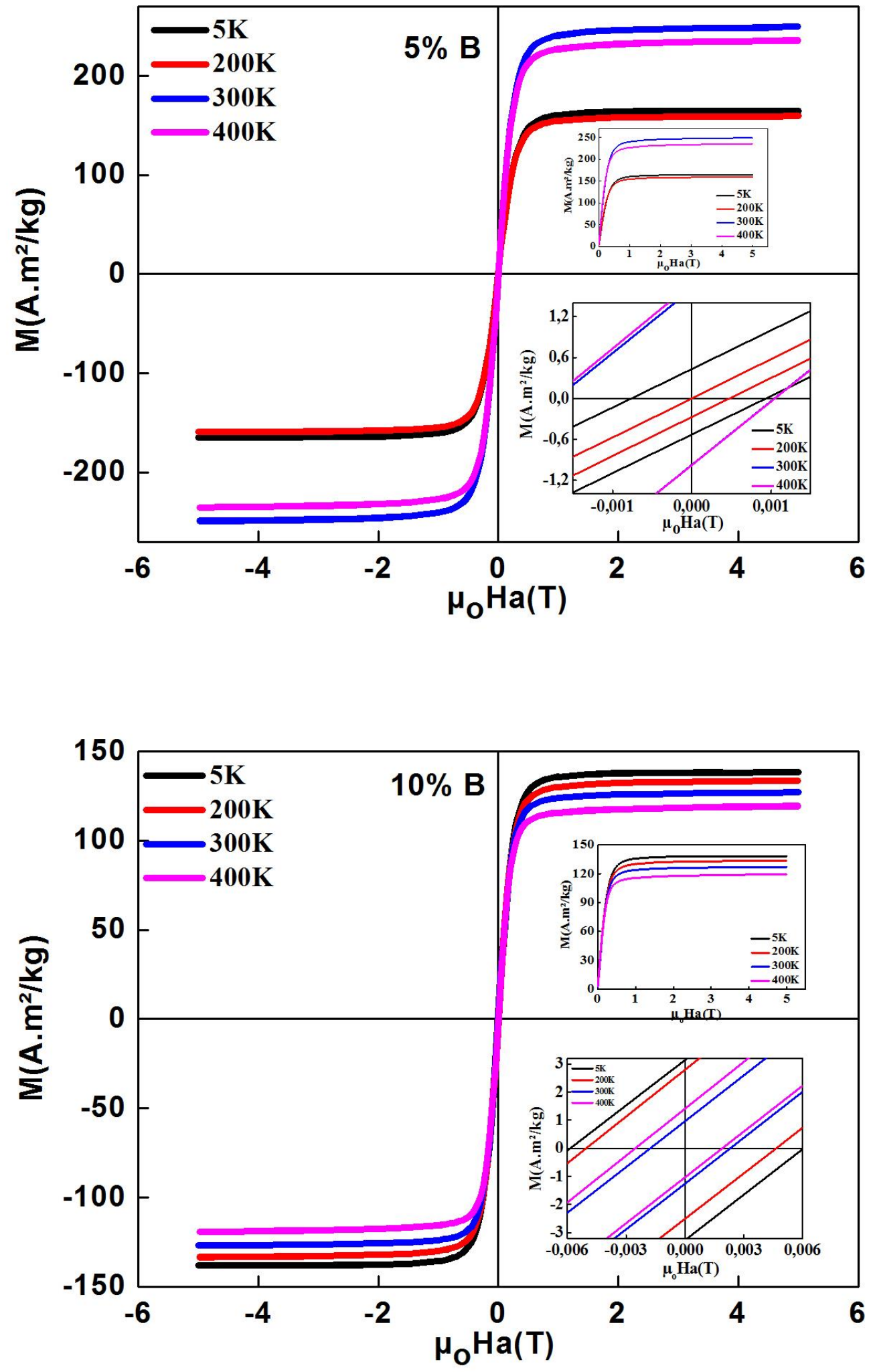

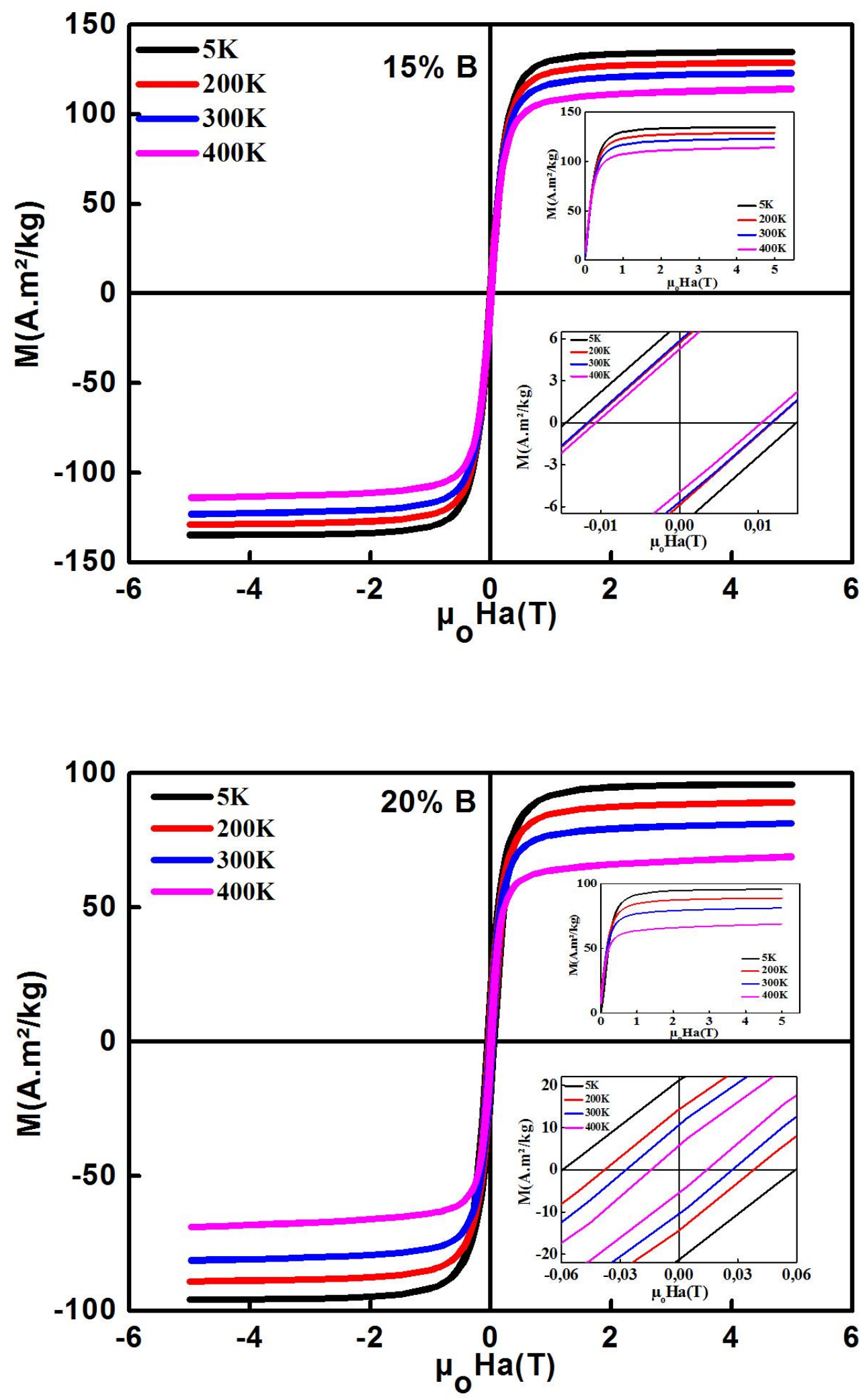

Figure 8 


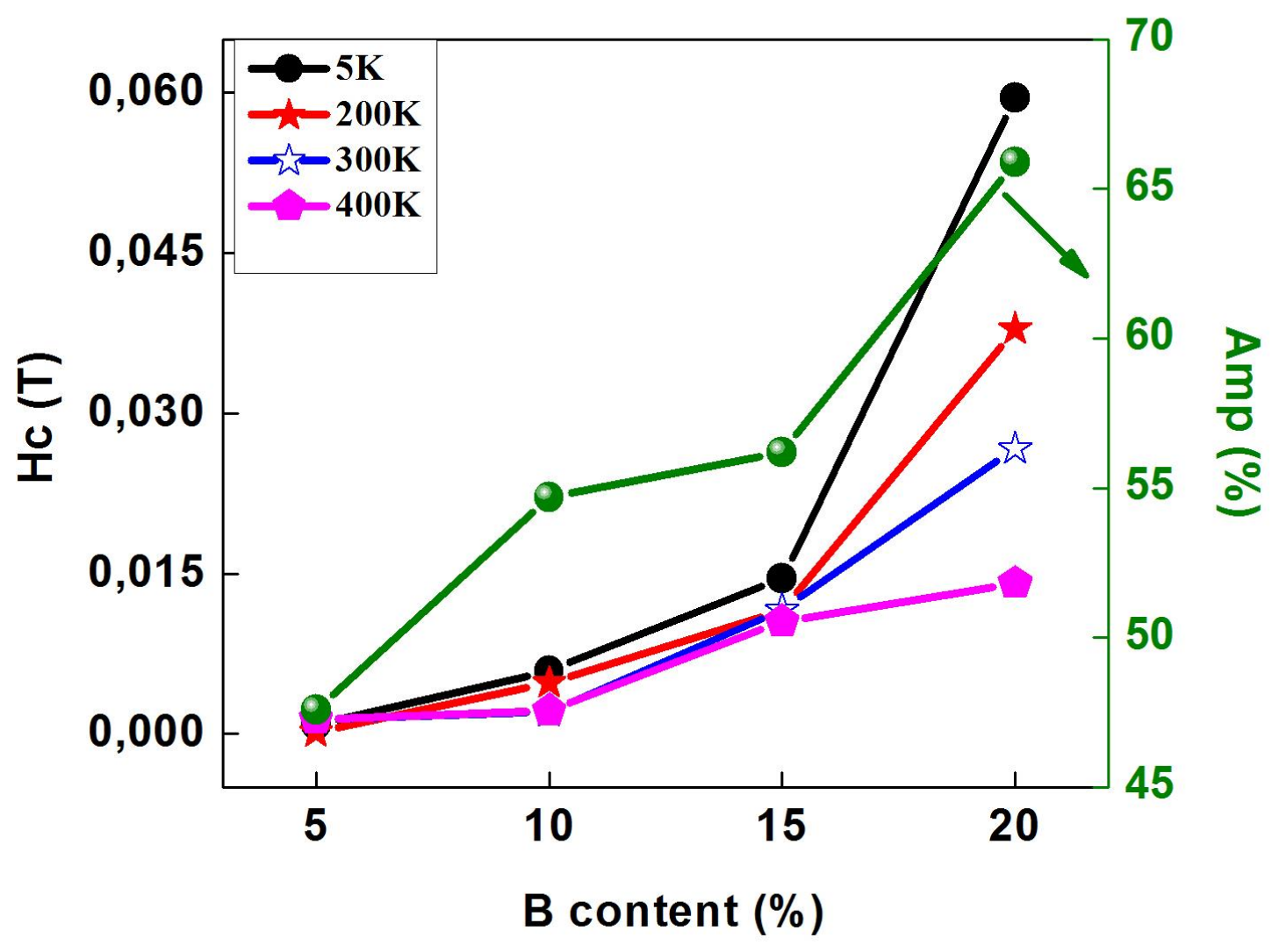

Figure 9 


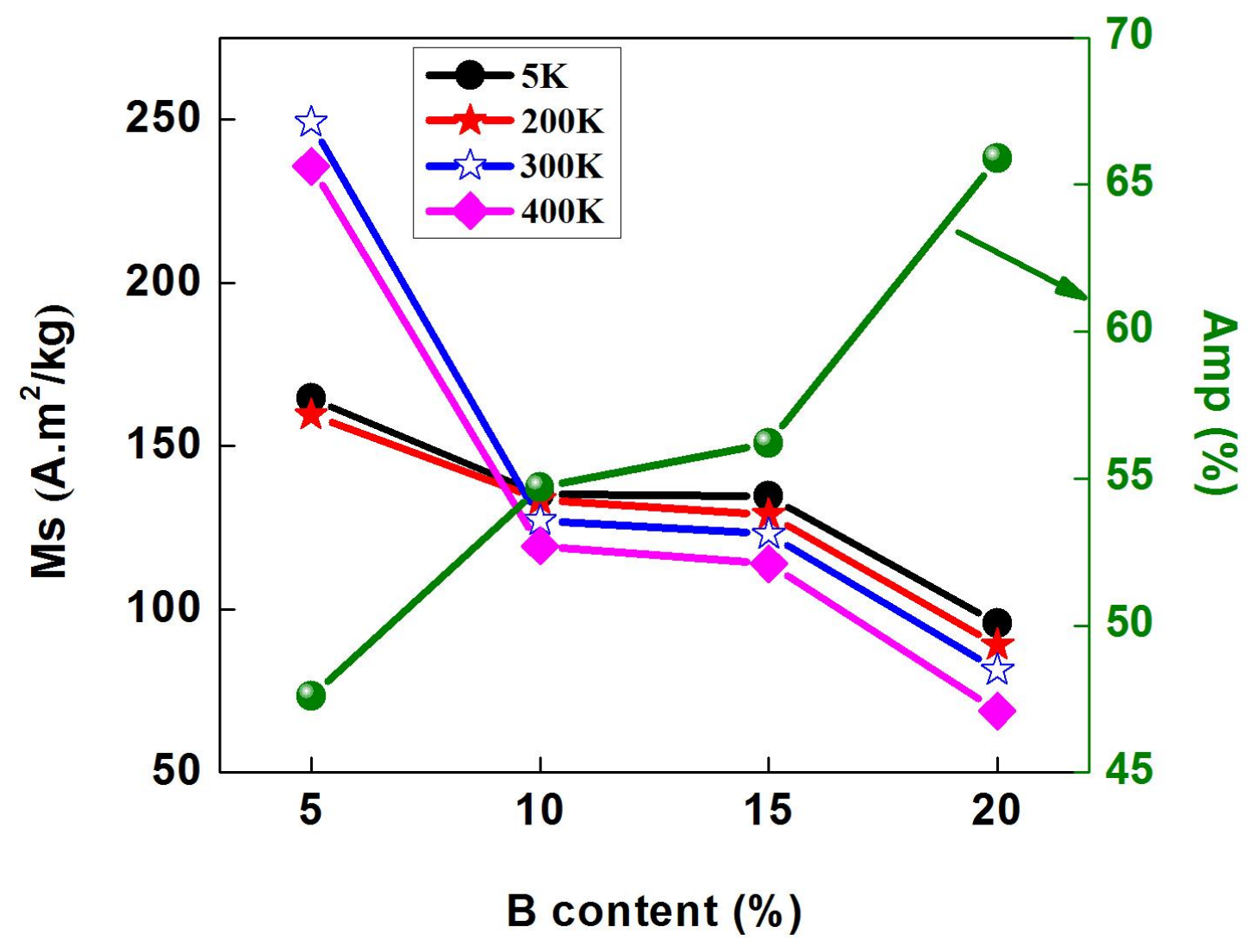

Figure 10

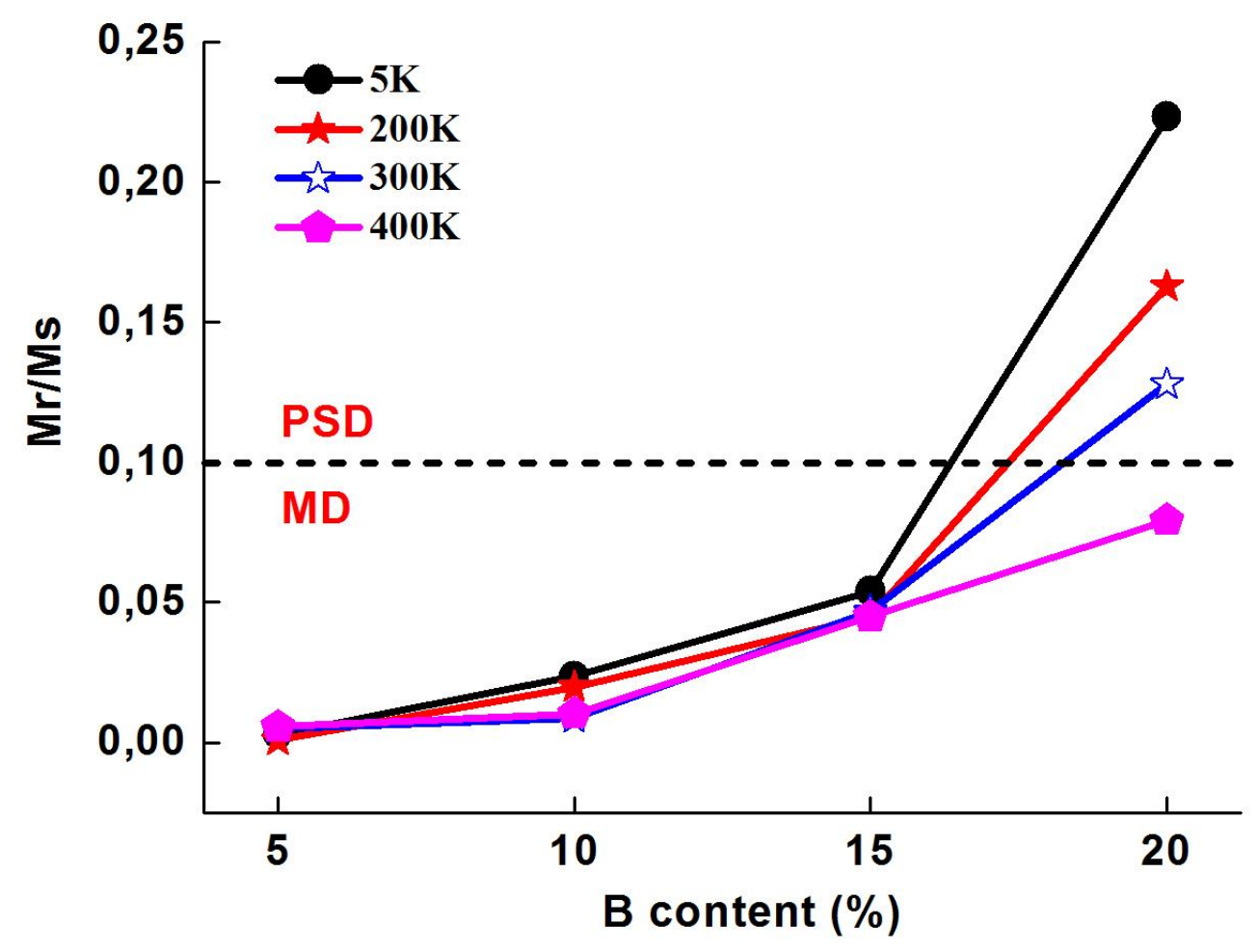


Figure 11

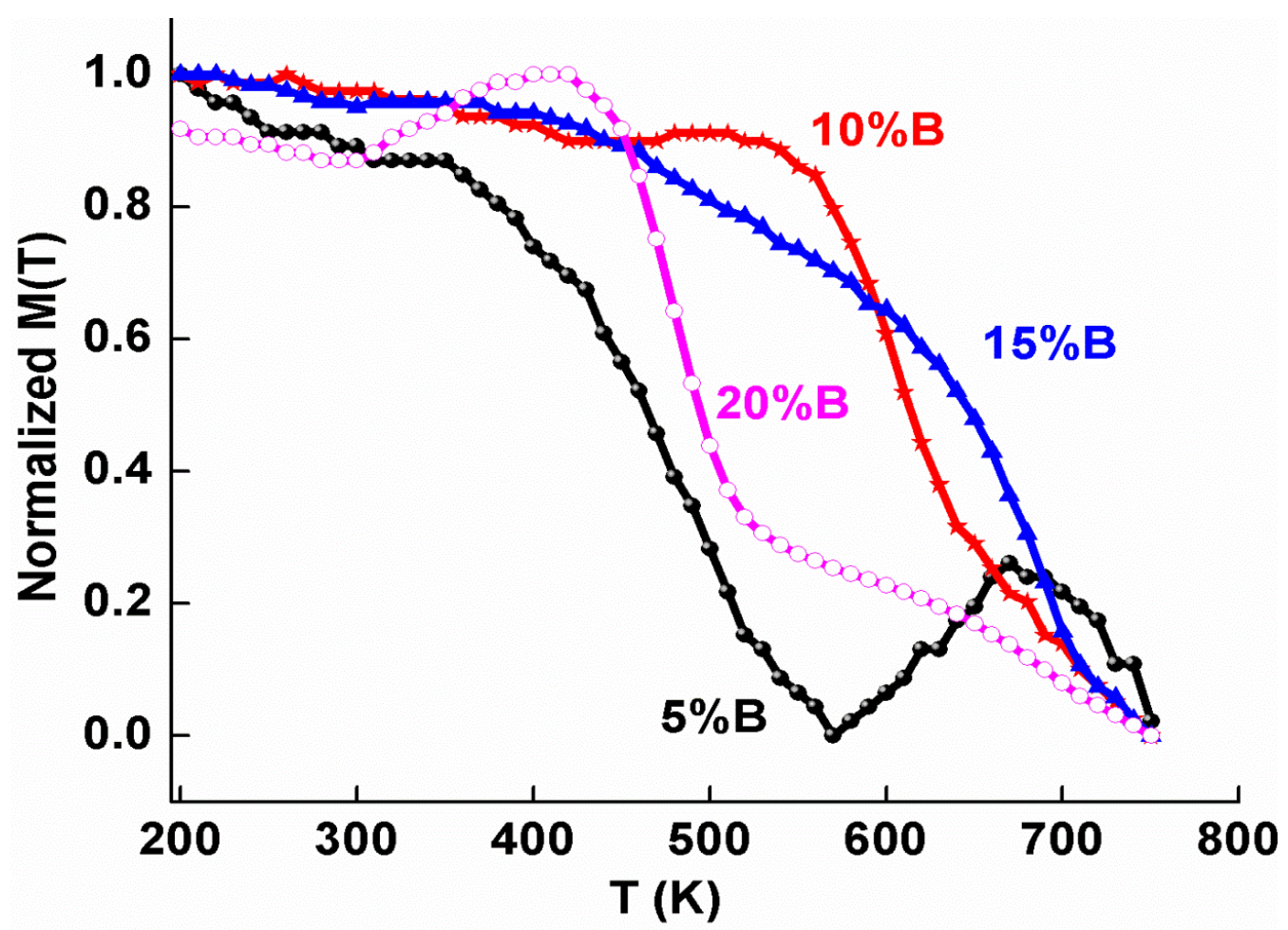

Figure 12

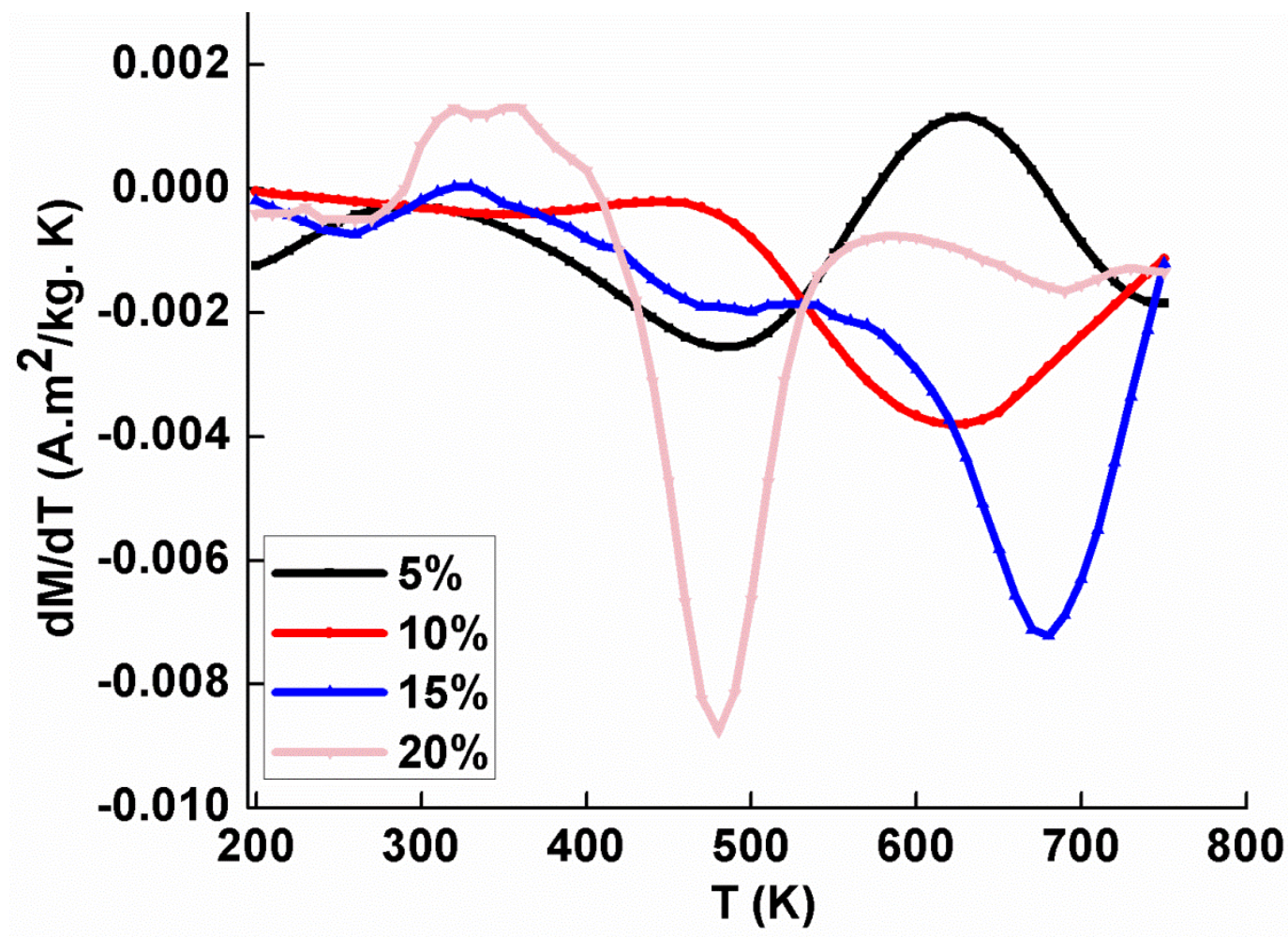

Figure 13 